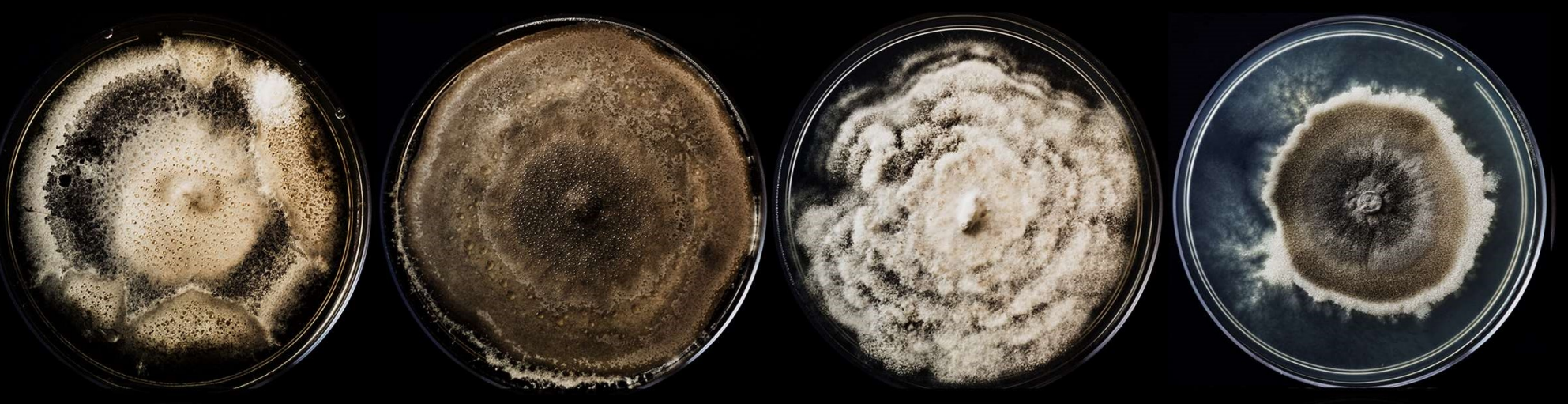

\title{
Metabolômica de fungos endofíticos associados à Baccharis oxyodonta DC. (Asteraceae): da quimiodiversidade à citotoxicidade
}

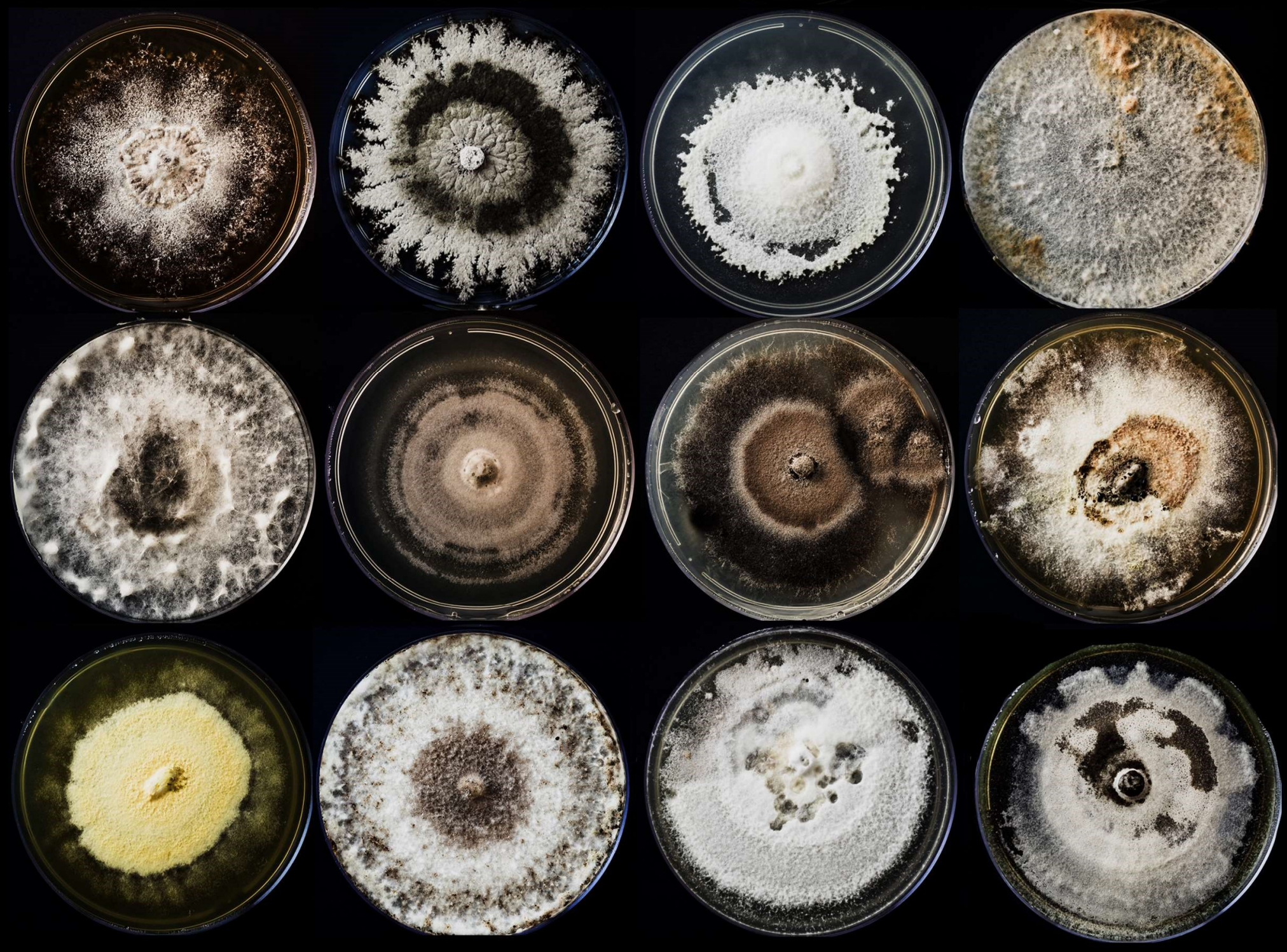

Eunizinis dos Santos Kawafune 


\title{
UNIVERSIDADE DE SÃO PAULO
}

\author{
INSTITUTO DE BIOCIÊNCIAS \\ Programa de Pós-Graduação em Ciências Biológicas \\ Departamento de Botânica
}

EUNIZINIS DOS SANTOS KAWAFUNE

Metabolômica de fungos endofíticos associados à Baccharis oxyodonta DC.(Asteraceae): da quimiodiversidade à citotoxicidade

Metabolomics of endophytic fungi associated with Baccharis oxyodonta DC. (Asteraceae): from chemiodiversity to cytotoxicity 
Metabolômica de fungos endofíticos associados à Baccharis oxyodonta DC.(Asteraceae): da quimiodiversidade à citotoxicidade

Metabolomics of endophytic fungi associated with Baccharis oxyodonta DC. (Asteraceae): from chemiodiversity to cytotoxicity

Dissertação apresentada ao Instituto de Biociências da Universidade de São Paulo, para obtenção do Título de Mestre em Botânica.

Orientador: Prof. Dr. Marcelo J. Pena Ferreira

São Paulo

2019 


\section{Ficha Catalográfica}

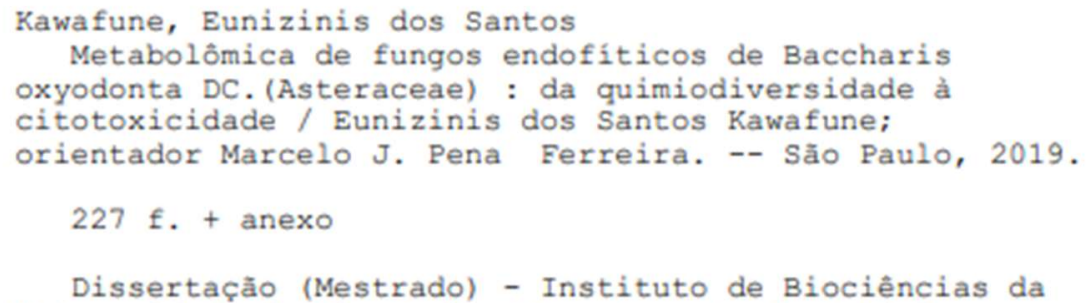

\section{Comissão Julgadora:}

Prof(a). Dr(a).

Prof(a). Dr(a).

Prof. Dr. Marcelo J. Pena Ferreira

Orientador(a) 


\section{Resumo}

Os microrganismos representam uma espetacular fonte de metabólitos bioativos que podem apresentar aplicações como agentes agrotóxicos, antibióticos, imunossupressores, antiparasitários, antitumorais, entre outros. Nesse grupo, os fungos endofíticos apresentam grande potencial na caracterização de substâncias bioativas, especialmente componentes citotóxicos. O objetivo geral deste trabalho foi contribuir com o conhecimento a respeito da diversidade química e biológica de fungos endofíticos associados aos indivíduos masculino e feminino de Baccharis oxyodonta DC. (Asteraceae). Para tal, os fungos endofíticos dos indivíduos feminino e masculino de $B$. oxyodonta foram isolados e identificados por sequenciamento da região ITS e construção de árvores filogenéticas. No indivíduo feminino foram isolados 28 fungos pertencentes aos gêneros Alternaria, Annulohypoxylon, Cercospora, Colletotrichum, Phomopsis e Preusia, e as famílias Dydimellaceae e Strophariaceae. Já do indivíduo masculino foram obtidos 20 fungos distribuídos entre os gêneros Alternaria, Aspergillus, Cladosporium, Penicillium, Periconia e Phomopsis. Para cultivo das cepas utilizou-se três meios de cultivos diferentes (arroz, BDA e Czapek). Após extração, as 136 amostras resultantes foram analisadas por CLAE/EM-EM e, a partir dos dados obtidos, foi realizada uma análise metabolômica que possibilitou a visualização do impacto das diferentes condições de cultivo no perfil metabólico das cepas. Dessa análise pode-se verificar que o meio de cultivo BDA gerou a maior diversidade metabólica e, também, foram identificadas diferentes classes de substâncias tais como, antraquinonas, xantonas, amidas, lactonas sesquiterpenicas, ácidos graxos, isocumarinas, dicetopiperazinas e policetídeos. Os extratos foram avaliados em relação ao potencial citotóxico, utilizando o ensaio do MTT, sendo 11 extratos considerados ativos frente a linhagem tumoral HCT-116 (carcinoma colorretal), quando testados na concentração de $50 \mu \mathrm{g} \cdot \mathrm{mL}^{-1}$. Com base nos resultados de citotoxicidade e do perfil metabólico, duas cepas, Alternaria sp. 1 e Phomopsis sp. 4, foram selecionadas para o cultivo em larga escala. Após procedimentos cromatográficos e análise espectral dos isolados, quatro componentes do extrato bruto de Alternaria sp. 1 foram identificados como alternariol, alternariol-metiléter, altenusina e 5'-metoxi-6-metil-bifenil-3,4,3'-triol e, a partir do extrato bruto de Phomopsis sp. 4 foram identificadas a sidowinina B, o ácido 8-hidroxi-6-metilxantona carboxílico, inéditos no gênero, e phomopsixantona, inédita em literatura. As substâncias foram avaliadas em relação a citotoxicidade entretanto apenas o alternariol exibiu atividade de inibição moderada frente a linhagem tumoral HCT-116.

Palavras-chave: Fungos endofiticos, Baccharis, metabolômica, redes moleculares, Produtos naturais, citotoxicidade. 


\section{Abstract}

Microorganisms represent a spectacular source of bioactive metabolites and they may have applications such as pesticides, antibiotics, immunosuppressants, antiparasitics, antitumor, among others. Endophytic fungi are a rich source of bioactive compounds, especially cytotoxic components. The objective of this work was to contribute to the knowledge about the chemical and biological diversity of endophytic fungi from male and female Baccharis oxyodonta DC. (Asteraceae). Thereby, the endophytic fungi of male and female individuals from $B$. oxyodonta were isolated and identified by sequencing of ITS region and using phylogenetic tree construction. Twenty-eight fungi belonging to the Alternaria, Annulohypoxylon, Cercospora, Colletotrichum, Phomopsis and Preusia genera, and the families Dydimellaceae and Strophariaceae were isolated from females. From the male, 20 fungi distributed among the genera Alternaria, Aspergillus, Cladosporium, Penicillium, Periconia and Phomopsis were obtained. Strains were cultivated using three different media (rice, BDA and Czapek). After extraction procedures, the resulting 136 samples were analyzed by HPLC/MS-MS and a metabolomic approach was performed to allow the visualization of the impact of different culture conditions on the metabolic profile of strains. From this analysis could be verified that BDA medium furnished the highest metabolic diversity and were identified different classes of compounds such as anthraquinones, xanthones, amides, sesquiterpene lactones, fatty acids, isocoumarins, diketopiperazines and polyketides. The extracts were evaluated for cytotoxic potential using the MTT assay. Eleven extracts tested at a concentration of $50 \mu \mathrm{g} \cdot \mathrm{mL}^{-1}$ were considered active against the HCT-116 tumor cell line (colorectal carcinoma). Based on the cytotoxicity and metabolic profile results, two strains, Alternaria sp. 1 and Phomopsis sp. 4, were selected for large-scale cultivation. After chromatographic procedures and spectral analysis of the isolated compounds, four components from Alternaria sp. 1 were identified as alternariol, alternariol methylether, altenusine and 5'-methoxy-6-methyl-biphenyl-3,4,3'-triol and from the crude extract of Phomopsis sp. 4 were identified sydowinin B, 8-hydroxy-6-methyl-xanthone carboxylic acid, unpublished in the genus, and a new compound phomopsixanthone. Isolated compounds were evaluated for cytotoxicity, however only alternariol showed moderate inhibition activity against the HCT-116 tumor cell line.

Keywords: Endophytic fungi, Baccharis, metabolomics, molecular networking, natural products, cytotoxicity. 


\section{Introdução}

\subsection{Fungos}

Nos sistemas de classificação mais antigos, os fungos eram incluídos no reino Plantae. Na época foram observadas características que os assemelhavam aos vegetais, entre elas, o fato de serem organismos sésseis. Apesar de se saber que, diferente das plantas, eles não realizavam fotossíntese (WHITTAKER, 1969; RAVEN et al., 1996). Atualmente, baseado nos avanços dos estudos de morfologia e biologia molecular, sabe-se que os fungos são evolutivamente mais próximos dos animais do que das plantas (BALDAUF, 2008). O reino Fungi foi proposto em 1969 por Robert Whittaker (WHITTAKER, 1969) e, desde então, nos sistemas de classificação posteriormente propostos, os fungos são considerados uma linhagem monofilética, como a proposta de Carl Woese, de 1977, que desenvolveu o sistema dos três domínios (WOESE \& FOX, 1977) e de Margulis, de 1982 (MARGULIS \& SCHWARTZ, 2001).

Os fungos são um grupo de organismos eucarióticos presentes dentro do domínio Eukarya (BALDAUF, 2008). Eles são organizados dentro do reino monofilético Fungi (BLACKWELL, 2011) abrigando os organismos denominados como "fungos verdadeiros", que é sustentado tanto por evidências morfológicas quanto moleculares. Existem discussões em relação à filogenia dos fungos, como o caso de inserção ou remoção de filos que vão ganhando força conforme ocorrem avanços nos estudos moleculares desses organismos, por exemplo, o caso da inclusão do grupo microsporidia dentro da filogenia dos fungos (JAMES et al., 2006). Uma proposta recente baseada em caracteres moleculares é apresentada na Figura 1 onde estão dispostos os filos do reino Fungi, nela é possível observar que os filos Ascomycota e Basiodiomycota formam um grupo irmão, denominado Dykarya, sendo os dois filos os mais derivados dentro da filogenia dos fungos (SPATAFORA et al., 2017). 


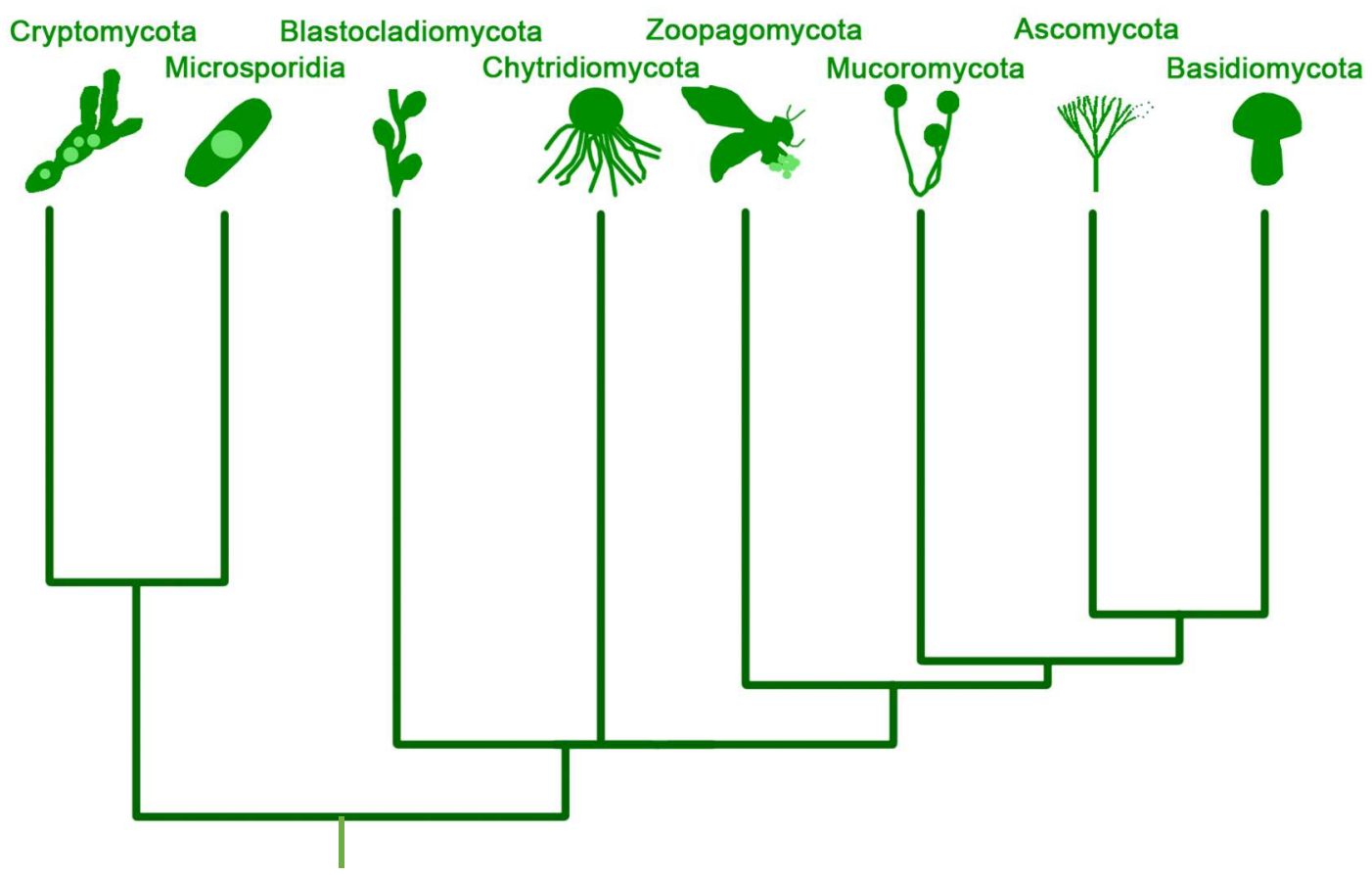

Figura 1. Filogenia da linhagem dos fungos a partir de dados moleculares (SPATAFORA et al., 2017; GAYA et al., 2018).

O registro fóssil mais antigo do grupo dos fungos pode ser um microfóssil preservado no xisto Grassy Bay Formation (Shaler Supergroup, Arctic Canadá), com aproximadamente 1.010-890 milhões de anos (Figura 2). Os espécimes de microfósseis de paredes orgânicas, nomeados de Ourasphaira giraldae, são multicelulares e apresentam filamentos septados com esferas terminais. Tais características aproximam O. giraldae do grupo Dikarya (Ascomycota e Basiodiomycota). Entretanto, a distribuição dos septos nos filamentos do fóssil encontrado é distinta do que acontece nesse grupo. As evidências sugerem que $O$. giraldae pode ter sido um ramo dentro do grupo Dikarya ou, um clado de fungos com algumas características bem semelhantes as encontradas nesse grupo (LORON et al., 2019). Atualmente, o fóssil de fungo mais antigo aceito data de 460 milhões de anos, do período Ordoviciano (REDECKER et al., 2000). O gênero Prototaxites está entre os registros fosses de fungos mais interessantes, atualmente a hipótese mais aceita desses organismos já extintos do período Devoniana é de se se tratam de fungos gigantes muito semelhantes em alguns aspectos com os fungos que realizam associações formando os líquens. Os registros fósseis apontam que esses seres podiam atingir até 8 metros de altura (HOBBIE \& BOYCE, 2010). 

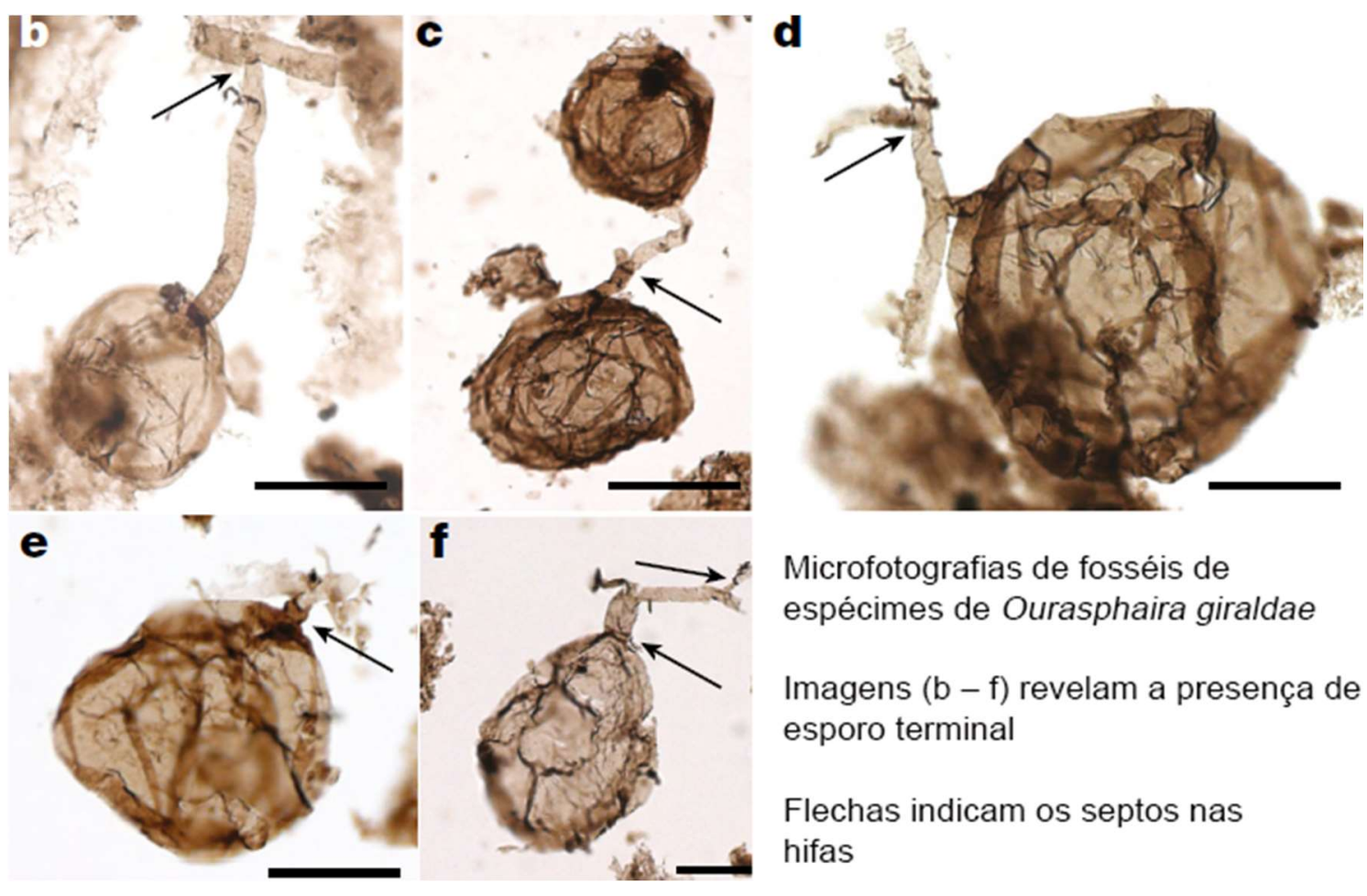

Microfotografias de fosséis de espécimes de Ourasphaira giraldae

Imagens $(b-f)$ revelam a presença de esporo terminal

Flechas indicam os septos nas hifas

Figura 2. Microfóssil de Ourasphaira giraldae preservado no xisto Grassy Bay Formation. Escala da barra $30 \mu \mathrm{m}$. Fonte: LORON et al., 2019.

Algumas características dos fungos são: (1) nutrição por heterotrofia, pois se alimentam através da absorção de nutrientes, que são obtidos por meio da secreção de enzimas digestivas no substrato; (2) quanto ao estado vegetativo, os fungos são formados, na maioria das vezes, por hifas que formam o micélio imóvel (WEBSTER \& WEBER, 2007) (Figura 3); (3) a presença de estruturas móveis, como flagelos, são observadas unicamente em estágios reprodutivos de alguns filos mais basais, como nos filos Blastocladiomycota e Chytridiomycota (JERÔNIMO et al., 2014); (4) a parede celular é formada por quitina e glucanos; (5) em relação a organização celular, os fungos podem ser tanto organismos multicelulares, como os fungos filamentosos, quanto organismos unicelulares como, por exemplo, as leveduras (RAVEN et al., 1996); (6) a reprodução, nesse grupo ocorre por alternância de geração, podendo ser assexuada e sexuada com a formação de esporos (WEBSTER \& WEBER, 2007). Na sexual, ocorrem os processos de plasmiogamia, cariogamia e meiose, já a assexual pode acontecer por meio de fragmentação das hifas, do micélio e por esporos (KANAGAWA \& NEVES, 2011). 


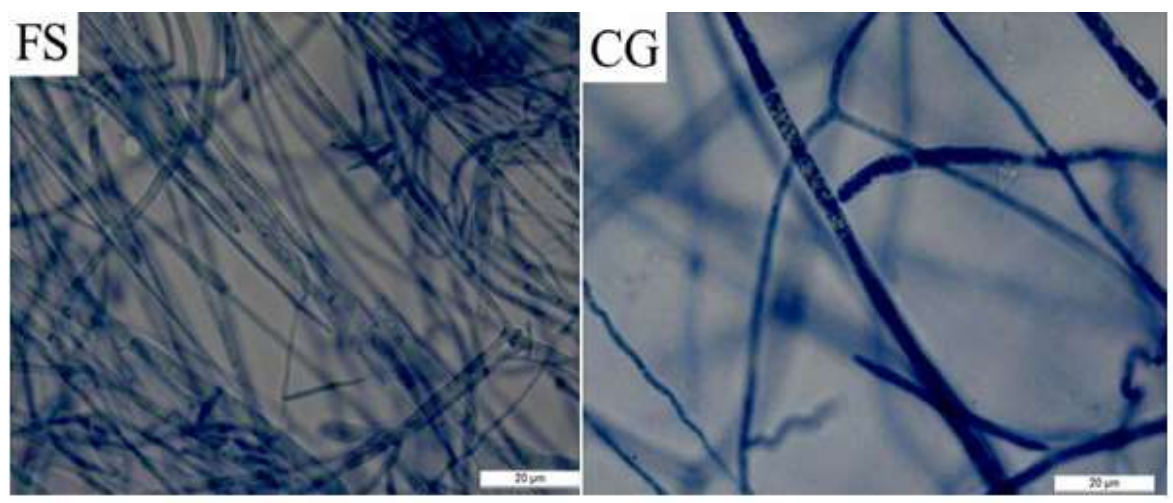

Figura 3. Exemplos de hifas de fungos. ( $F S=$ Fusarium solani e CG = Colletotrichum gloeosporioides) Fonte: SOUZA et al., 2015.

Os fungos apresentam distribuição cosmopolita (WEBSTER \& WEBER, 2007) e estão presentes em ambientes terrestres (HAWKSWORTH, 2004) como, também, em ambientes aquáticos (TAKAHASHI et al., 2008). Do ponto de vista ecológico, os fungos podem desempenhar papéis muito importantes, como de decompositores ou saprófitos, que estão envolvidos com a reciclagem da matéria orgânica, através do consumo de matéria orgânica morta ou em decomposição (RAVEN et al., 1996; WEBSTER \& WEBER, 2007). Eles podem desenvolver associações de mutualismo e simbiose com algas e cianobactérias, formando os líquens (HONDA \& VILEGAS, 1998) e com plantas terrestres, formando as associações de micorrizas (entre a raiz da planta e o fungo) (BERBARA et al., 2006). Podem ser predadores, assim como o caso de fungos nematófagos (CASTRO et al., 2003) e parasitas, tanto de plantas quanto de animais (RAVEN et al., 1996; WEBSTER \& WEBER, 2007).

Além de possuírem um importante papel ecológico, eles também são importantes economicamente. Seu uso vai desde recursos alimentícios, como os cogumelos comestíveis e da levedura, Saccharomyces cerevisiae, utilizada no processo de fermentação de bebidas alcoólicas e no fermento biológico, empregado na fabricação de pães, até o uso de metabólitos que são produzidos por esses organismos na medicina, por exemplo, a penicilina descoberta por Fleming em 1928 (PEREIRA \& PITA 2005; KANAGAWA \& NEVES, 2011)

Estima-se que há aproximadamente 144.140 espécies de fungos descritas (SPATAFORA et al., 2017; CANON et al., 2018). Entretanto, alguns trabalhos apontam a existência de cerca de 1,5 milhão de espécies de fungos (HAWKSWORTH, 2001) e outros indicam a existência de cerca de 5 milhões de espécies (BLACKWELL, 2011). Considerando essa estimativa de 5 milhões e o total de espécies já descritas, o 
conhecimento sobre as espécies de fungos existentes atualmente seria apenas de $3 \%$ (BLACKWELL, 2011; SPATAFORA et al., 2017; CANON et al., 2018). Um dos fatores levados em consideração para a construção dessas estimativas é a presença de fungos em plantas, como o caso dos fungos endofíticos, que são fungos que vivem no interior do tecido da planta sem causar prejuízos ao hospedeiro (AZEVEDO, 1998; BLACKWELL, 2011). Visto que, das aproximadamente 300.000 espécies de plantas que existem na Terra, cada uma pode ser hospedeira de novas espécies de fungos em uma taxa de 6:1, o que demonstra que a diversidade desses organismos é bem alta (STROBEL \& DAYSE, 2003; BLACKWELL, 2011).

Das espécies de fungos já descritas, o filo Ascomycota é o que apresenta a maior diversidade, com mais de $60 \%$ das espécies já registradas, seguido por Basiodiomycota, com aproximadamente $35 \%$ e os outros filos correspondendo a $5 \%$ (Figura 4) (SPATAFORA et al., 2017; CANON et al., 2018).

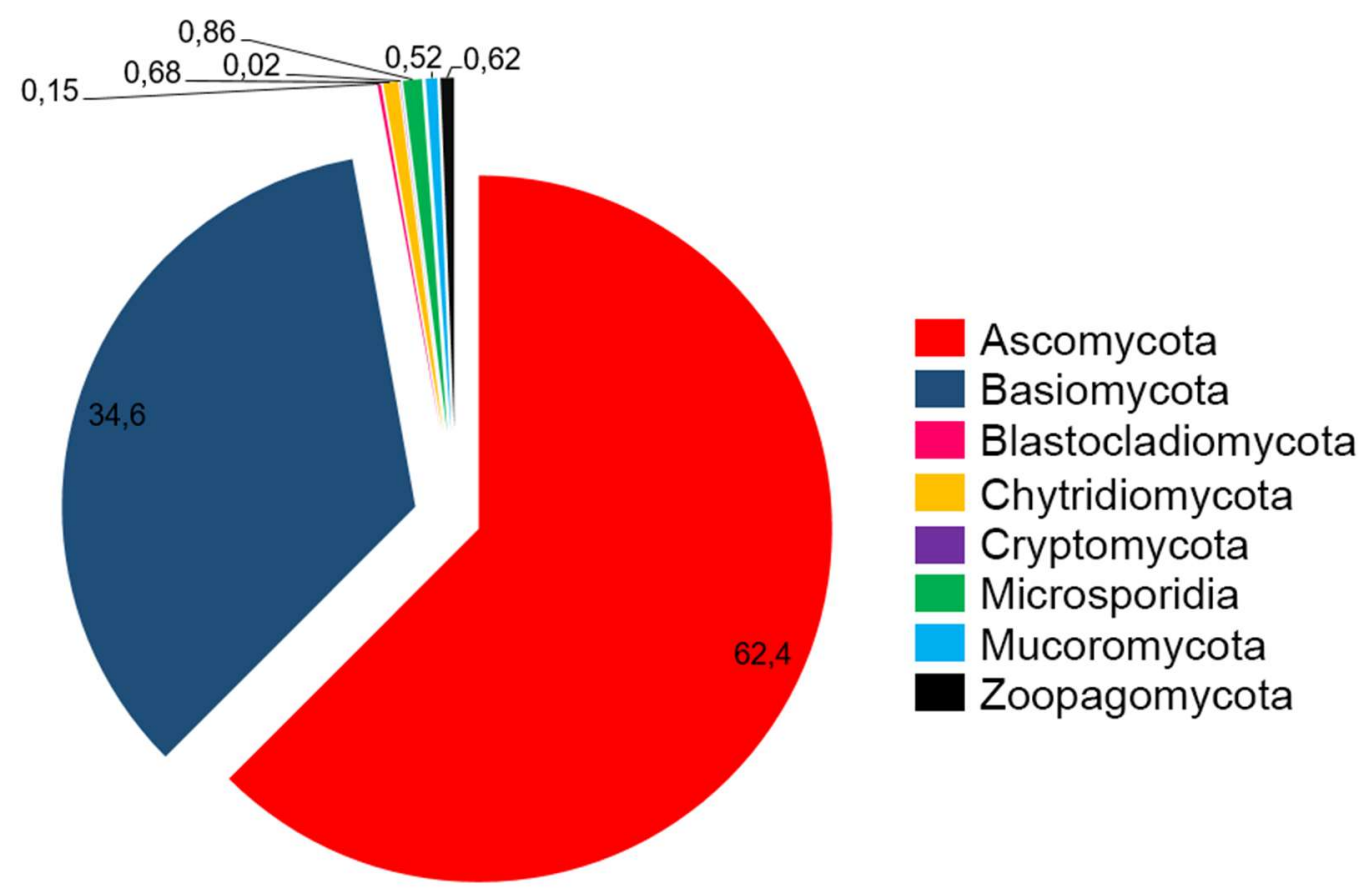

Figura 4. Distribuição de espécies de fungos descritas nos oito filos existentes. Gráfico baseado nos dados: SPATAFORA et al., 2017; CANON et al., 2018

Já no Brasil, segundo o Flora do Brasil Online 2020, existem 5.264 espécies de fungos stricto sensu descritas, o que corresponde a $4 \%$ do número de espécies descritas mundialmente, sendo 51 espécies endêmicas. A maior parte dos fungos pertence ao filo Basidiomycota, seguido pelo filo Ascomycota (Figura 5); e as regiões com maior número de espécies descritas são nordeste e sudeste (Figura 6). Já em 
relação aos biomas, a Mata atlântica é que a apresenta maior número de espécies, seguida da Amazônia e da Caatinga (Figura 7).
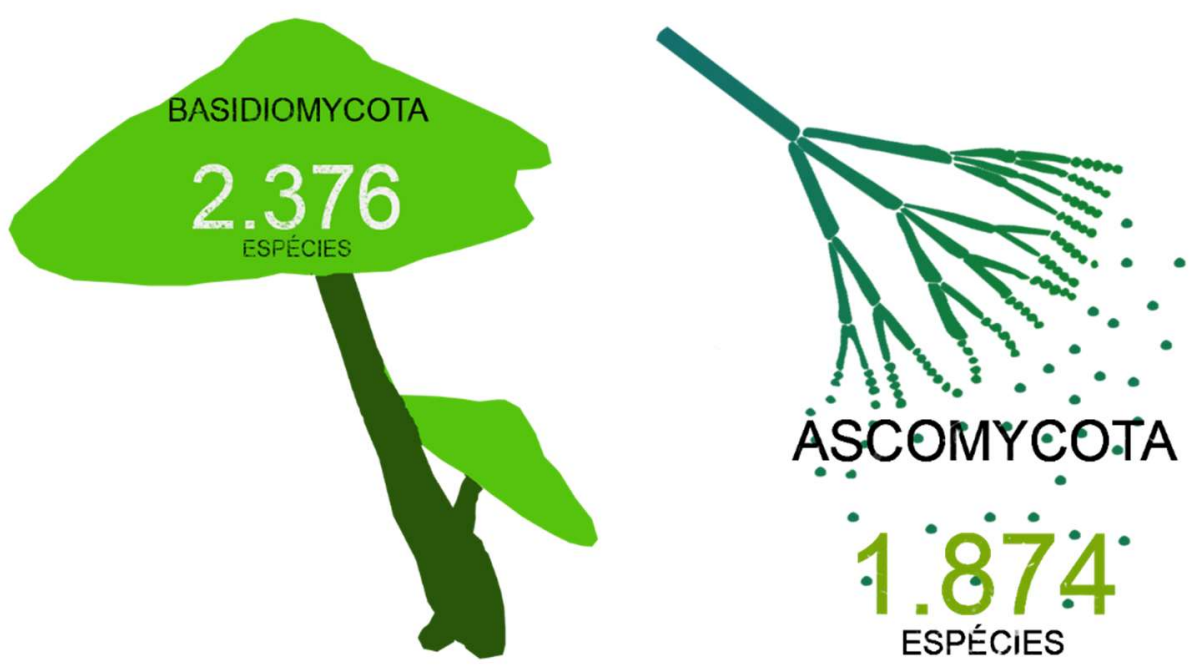

Figura 5. Quantidade de espécies dos filos Ascomycota e Basidiomycota descritas no Brasil. Esquema baseado nos dados: Flora do Brasil Online 2020.

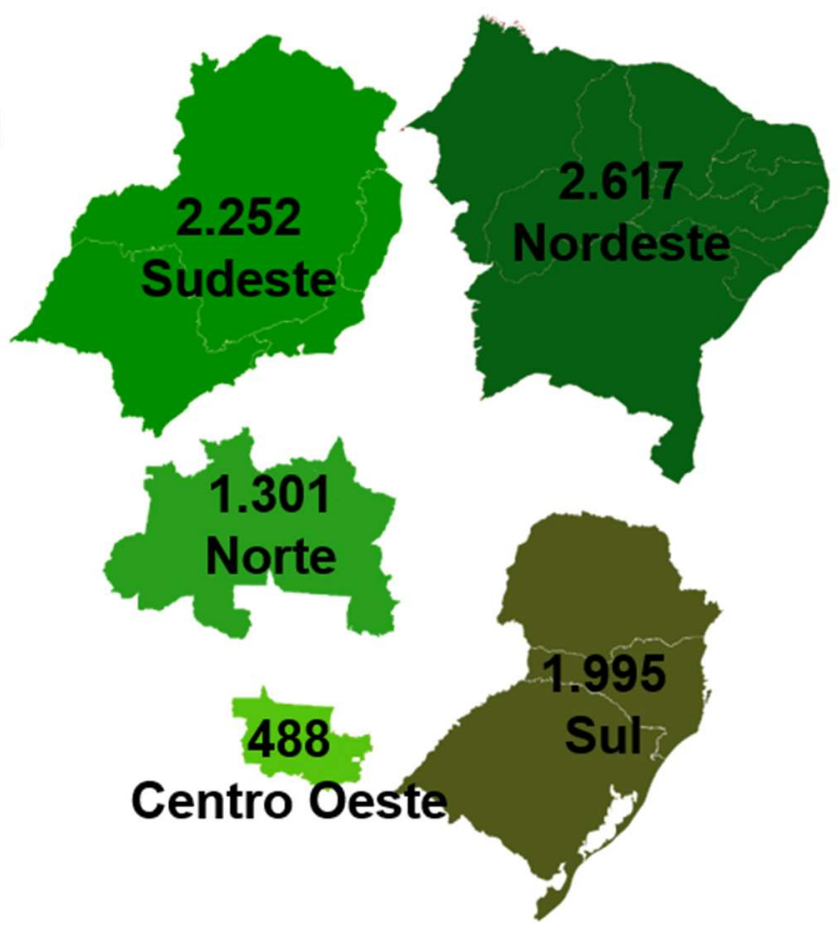

Figura 6. Distribuição das espécies de fungos por regiões do Brasil. Esquema baseado nos dados: Flora do Brasil Online 2020. 


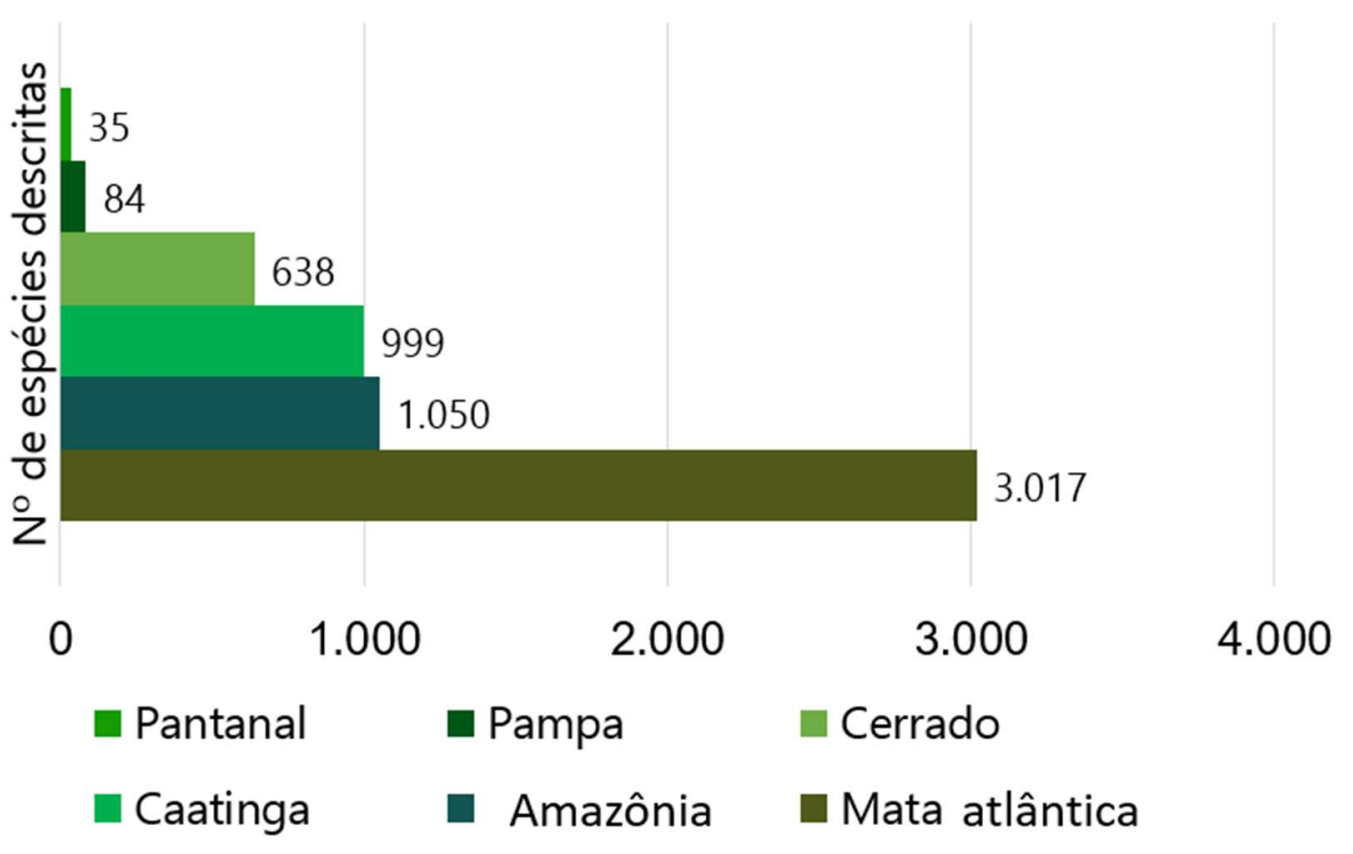

Figura 7. Quantidade de registros de espécies de fungos por biomas no Brasil. Esquema baseado nos dados: Flora do Brasil Online 2020.

\subsection{Fungos endofíticos}

O termo endofítico vem do grego $($ endon $=$ dentro e phyton $=$ planta $) \mathrm{e}$ literalmente significa "dentro da planta" (SCHULZ \& BOYLE, 2005). Durante o século XIX, o botânico alemão Heinrich Friedrich Link foi o primeiro a realizar uma descrição de endofíticos. Naquela época, o termo utilizado era "Entophytae", para descrever um distinto grupo de fungos parcialmente parasitas vivendo dentro de plantas (HARDOIM et al., 2015). Foi somente com a definição feita pelo cientista alemão Heinrich Anton de Bary, em 1866, que houve a distinção dos microrganismos patógenos de endófitos, sendo os últimos considerados assintomáticos (AZEVEDO, 1998). Atualmente, os termos endofítico ou endófito podem ser definidos, como: "todos os microrganismos, cultiváveis ou não, que habitam o interior de tecidos de plantas e que não causam prejuízos aos seus hospedeiros" (AZEVEDO, 2014). Os microrganismos endofíticos vivem ou passam parte de sua vida no interior dos tecidos do hospedeiro (podendo ser um organismo vegetal ou animal, de ambiente terrestre ou marinho), sem causar injúrias (ZHANG et al., 2009; HARDOIM et al., 2015). Em plantas, esses microrganismos podem habitar as partes aéreas, como folhas, flores e caules e, também, regiões subterrâneas, como as raízes (SCHULZ \& BOYLE, 2005). 
A definição do que é fungo endofítico depende muito do momento no qual a relação do fungo com a planta é analisada, visto que um fungo que apresenta um comportamento caracterizado como de um endofítico, pode, em outras situações, apresentar diferentes comportamentos, tal como o parasitismo (HARDOIM et al., 2015). Por exemplo, a presença do fungo Fusaruim verticillioides no milho pode ser patogênica, ou gerar benefícios ao hospedeiro (BACON et al., 2008). O balanço entre esses dois diferentes comportamentos do microrganismo, depende, entre vários fatores, do genótipo do hospedeiro e da ocorrência de fatores abióticos estressantes, que reduzem o fitness da planta, resultando, assim, na distorção do delicado balanço entre a ocorrência da patogenicidade causada pelo fungo e a produção de micotoxinas benéficas a planta (BACON et al., 2008; HARDOIM et al., 2015). Portanto, no exemplo citado, a presença do fungo, Fusaruim verticillioides pode gerar doenças no milho, mas pode, também, nas condições adequadas, suprimir o crescimento de outro fungo, Ustilago maydis, protegendo o vegetal da doença carvão-do-milho, causada pela patogenicidade desse último organismo (ESTRADA et al., 2012).

Os microrganismos endofíticos são amplamente distribuídos e vêm sendo achados em todas a espécies de plantas (AZEVEDO, 1998; STROBEL et al., 2005). Os que são mais frequentemente isolados de plantas são os fungos (STROBEL et al., 2005). Os fungos endofíticos estão presentes em briófitas, pteridófitas, gimnospermas e angiospermas, ou seja, desde os grupos mais basais das plantas terrestres até os mais derivados (HARDOIM et al., 2015) (Figura 8).
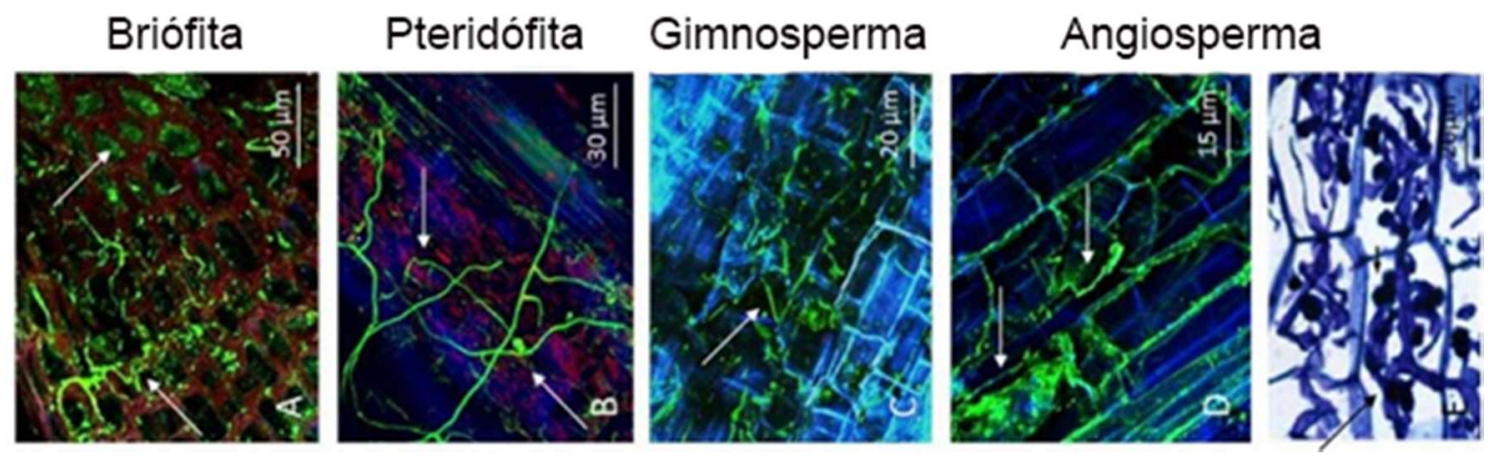

Figura 8. Fungos endofíticos (apontados pelas setas) presentes em diferentes grupos de plantas terrestres (A: Sphagnum sp., B: Samambaia, C: Pinus sp., D: Trifolium sp. e E: Eleutherococcus sieboldianus) Fonte: HARDOIM et al., 2015.

Registros fósseis apontam que o começo da relação entre fungos endofíticos e plantas terrestres, provavelmente ocorreu no início da colonização do ambiente terrestre (HARDOIM et al., 2015). O registro fóssil mais antigo encontrado de um representante 
de fungo com características semelhantes àquelas que são vistas em fungos micorrízicos arbusculares (FMAs) (Figura 9), foram encontrados nas rochas dolomíticas em Wisconsin e têm uma idade estimada de 460 milhões de anos, pertencentes ao período Ordoviciano. Apesar de não haver evidência de que os fungos desses fósseis estivessem associados com plantas, o fato de existirem registros fósseis de plantas terrestres no período Ordovaciano e ser conhecida a capacidade de grupos extintos de briófitas de realizarem interações semelhantes às de micorriza, podem sugerir a possibilidade de uma possível interação desses fungos encontrados com os primeiros grupos de plantas terrestres (REDECKER et al., 2000). Já outro registro fóssil localizado no Cherte de Rhynie da Escócia, datado no início do Devoniano, apresenta três tipos de diferentes fungos endofíticos presentes em uma planta já extinta, a Nothia aphylla (Figura 10) (KRINGS et al., 2007). Essas evidências fósseis sugerem que o início da relação entre fungos endofíticos, principalmente os semelhantes a FMA's, e as plantas, possivelmente se desenvolveu a partir dos primeiros ancestrais das plantas terrestres (SIMON et al., 1993). Existem hipóteses de que a presença dos fungos endofíticos semelhantes aos FMA's nos ancestrais das plantas terrestres, teria sido um dos fatores benéficos para as plantas durante a conquista do ambiente terrestre, como por meio do aumento na aquisição de nutrientes do solo, propiciando, dessa forma, a evolução dessa relação entre fungos endofíticos e plantas (SIMON et al., 1993; HARDOIM et al., 2015).
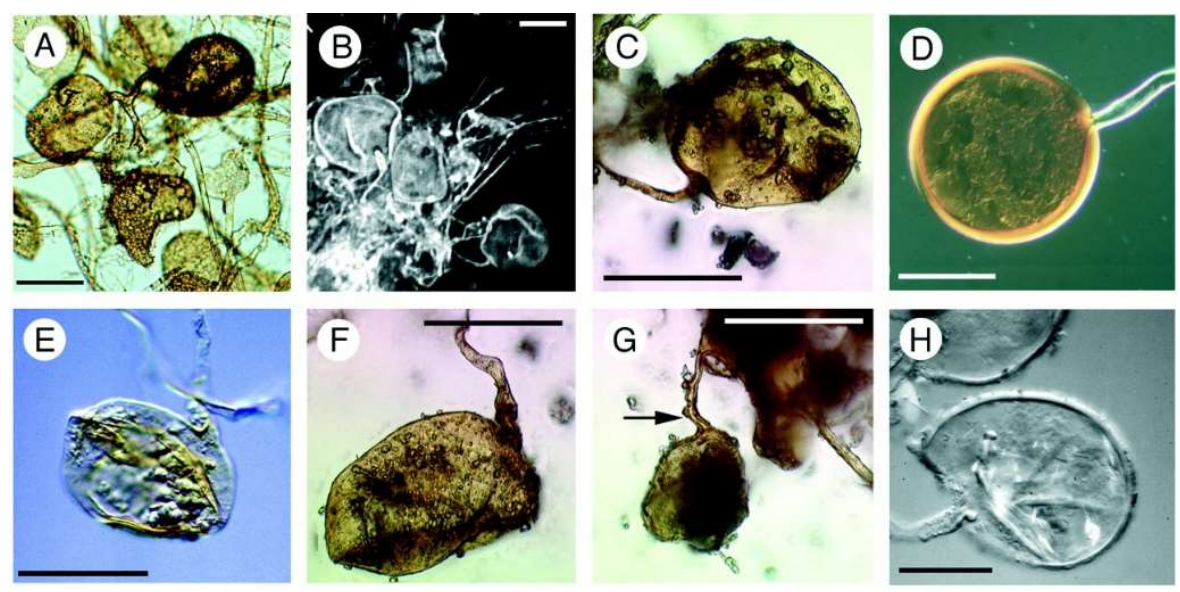

Figura 9. A, B, C, E, F e G: Hifas e esporos fósseis. D e H: Exemplo de esporos formados por um fungo existente do gênero Glomus sp. Nota-se a semelhança entre os registros fósseis encontrados com fungos existentes. Todas as barras de escala estão em 50 mm. Fonte: REDECKER et al., 2000. 

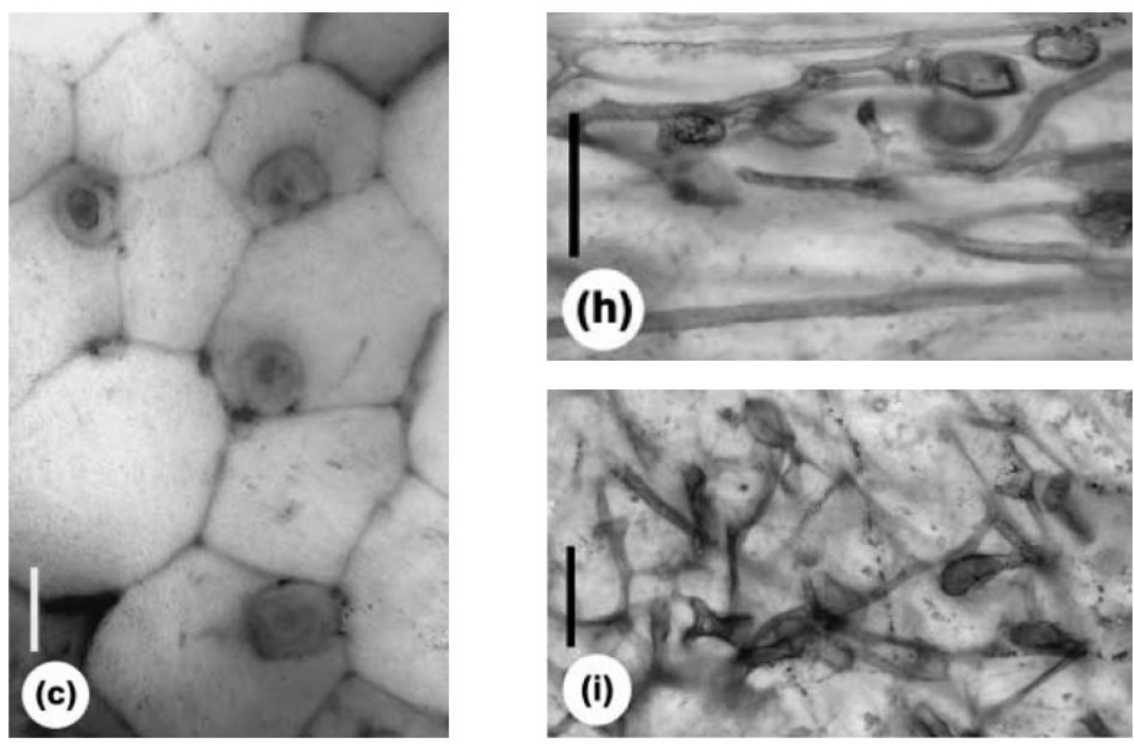

Figura 10. Fósseis da planta extinta Nothia aphylla. É possível visualizar a presença de hifas espalhadas pelo tecido da planta. Escala: $\mathrm{c}=$ bar, $30 \mu \mathrm{m} \mathrm{h,} \mathrm{i} \mathrm{=} \mathrm{bar,} 100 \mu \mathrm{m}$. Fonte: KRINGS et al., 2007

Existem duas formas de transmissão e/ou colonização dos tecidos vegetais pelos fungos endofíticos: a horizontal e a vertical.

A transmissão horizontal pode ocorrer através da entrada do fungo a partir de injúrias presentes na zona radicular da planta, que podem ser causadas pelo crescimento das raízes e a emergência de raízes secundárias, através de esporos aerotransportados que penetram no tecido do vegetal por via de fissuras causadas por animais, pragas, predadores, ou, até mesmo, o manuseio da planta por humanos ou máquinas e por intermédio de aberturas naturais presentes nesses organismos, como o caso dos estômatos e hidatódios (AZEVEDO, 1998; CHAPLA et al., 2012; HARDOIM et al., 2015).

A transmissão vertical acontece entre gerações por via de sementes. Neste caso, as hifas do fungo endofítico conseguem penetrar o tecido do ovário e do óvulo da planta e permanecem durante os estágios de maturação da semente e consequentemente do embrião. Após a maturação, as hifas estão amplamente espalhadas no embrião e em seguida a germinação, as hifas se espalham nos tecidos, conforme vai acontecendo o crescimento do vegetal hospedeiro. Esse tipo de transmissão é documentado em gramíneas, como Festuca arundinacea e Lolium perenne (PHILIPSON \& CHRISTEY, 1986; HARDOIM et al., 2015). Essa transmissão pode ocorrer também via transporte do fungo por intermédio do grão de pólen, com a entrada do fungo através do crescimento do tubo polínico no órgão reprodutor da planta mãe (HODGSON et al., 2013). 
A relação simbiótica e assintomática entre o endofítico e a planta, pode conferir a ambos os organismos diversas vantagens adaptativas. Para o fungo, a presença na planta é interessante, devido a aquisição de nutrientes e a proteção que o ambiente em que ele está presente oferece (CHAPLA et al., 2012). Já para o vegetal, a presença do fungo endofítico pode gerar proteção em relação a fatores abióticos, como seca e alta salinidade, fatores bióticos, tal como proteção em relação a predadores, e outros benefícios, por exemplo, maior habilidade competitiva e maiores taxas de desenvolvimento que podem acarretar em maior ganho de massa e produção de sementes (SCHARDL \& PHILLIPS, 1997; RODRIGUEZ et al., 2008; HARDOIM et al., 2015). É notável que espécies de plantas selvagens necessitam de microrganismos endofíticos, como os fungos, para sobrevivência e tolerância ao estresse que esses vegetais são expostos (RODRIGUEZ \& REDMAN, 2008). Segundo Rodriguez e colaboradores (2008), gramíneas nativas de regiões de costa, necessitam da presença de fungos endofíticos para conseguirem sobreviver as condições de estresse que esse local possui, como alta salinidade. O trabalho desses pesquisadores, mostra a importância da presença dos fungos endofíticos nos vegetais de maneira que essa relação, em alguns casos, se torna vital para o crescimento e sobrevivência das plantas em ambientes com fatores muito estressantes para elas.

É conhecida a habilidade dos fungos endofíticos de produzir metabólitos e utilizálos como defesa química em resposta à pressão exercida por fatores abióticos ou bióticos. Essa pressão pode ser causada pela presença de outros endófitos, fitopatógenos ou predadores (AZEVEDO, 1998; CHANDRA, 2012; ALY et al., 2013). Essas substâncias produzidas pelos fungos endofíticos são um dos fatores que capacitam esses organismos no beneficiamento/ favorecimento de seu hospedeiro em relação a proteção e resistência a pragas, herbivoria, doenças e a tolerância em relação a fatores abióticos estressantes (CLAY, 1988; GAO et al., 2005; HARDOIM et al., 2015). Um exemplo que pode ser dado é o caso da produção de alcaloides por fungos endofíticos associados a gramíneas, que fornecem uma série de mecanismos de proteção e resistência para as plantas em relação a pragas e a herbivoria, as protegendo tanto de ataques de insetos quanto de mamíferos (CLAY, 1988).

\subsection{Metabólitos de fungos endofíticos}

Os microrganismos representam uma espetacular fonte de metabólitos bioativos que podem apresentar amplas aplicações tais como agentes agrotóxicos, antibióticos, 
imunossupressores, antiparasitários, antitumorais, entre outros (BLACKWELL, 2011). Os fungos, em particular, representam uma importante fonte de metabólitos que têm ação farmacológica de amplo espectro desde antibióticos, como a penincilina, até redutores de colesterol humano como, por exemplo, o caso das estatinas, que entre o período de 1981 e 2006 lideraram o rank de fármacos mais vendidos, possuindo a primeira posição ocupada pela lovastatina e a segunda pela sinvastatina (Figura 11) (GANESAN, 2008; KANAGAWA \& NEVES, 2011).
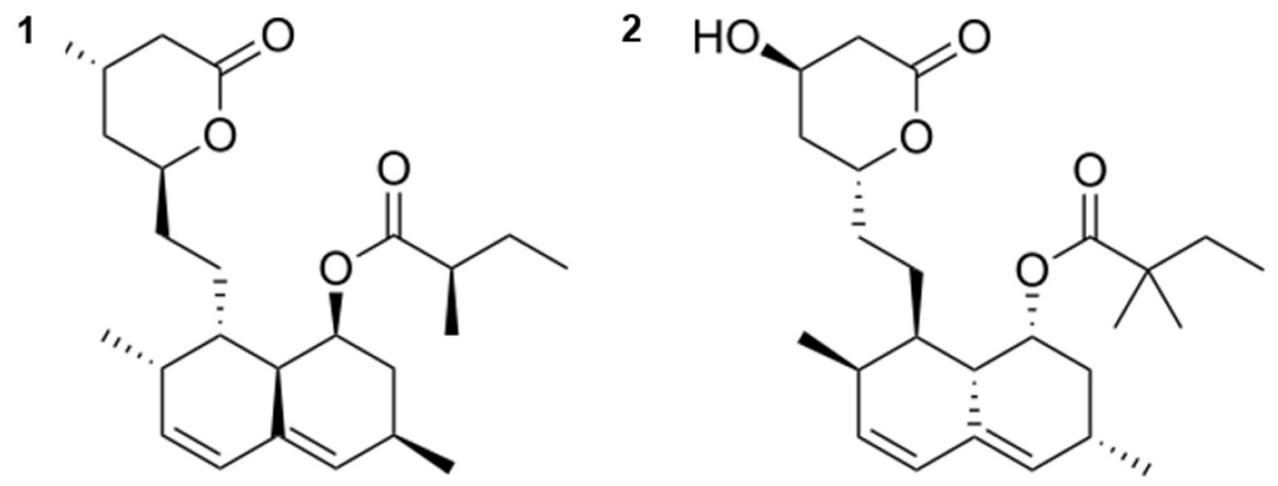

Figura 11. Lovastatina (1) e sinvastatina (2).

A grande parte dos metabólitos de fungos podem ser divididos em três grandes categorias: os policetídeos derivados de acetil-CoA, como a lovastatina, os peptídeos não ribossomais de aminoácidos, sendo a pelicilina $\mathrm{G}$ um dos seus representantes e os terpenoides formados por unidades de isopentenil-difosfato (IPP) e dimetilalil-difosfato (DMAPP), como o aristolochene (Figura 12). Cada uma das classes está associada com diferentes tipos de enzimas, as policetídeo sintases (do inglês: polyketide syntase (PKSs)), as peptídeo sintases não ribossomais (do inglês: non-ribosomal peptide synthetase (NRPs)) e as terpeno ciclases e sintases (do inglês: terpene cyclase/synthase). Os genes responsáveis pela codificação dessas enzimas estão arranjados em aglomerados de genes biossintéticos denominados de "clusters" (biosynthetic gene cluster (BGS)) (THROCKMORTON et al., 2015; KELLER, 2019).<smiles>CCC(C)C(=O)O[C@H]1C[C@H](C)C=C2C=C[C@H](C)[C@H](CC[C@@H]3C[C@@H](O)CC(=O)O3)[C@H]21</smiles><smiles>CC1(C)S[C@@H]2[C@H](NC(=O)Cc3ccccc3)C(=O)N2[C@H]1C(=O)O</smiles><smiles>C=C(C)C1CC=C2CCC[C@H](C)[C@]2(C)C1</smiles> 
Figura 12. Lovastatina (1), pelicilina G (2) e aristolochene.

O número de metabólitos secundários produzidos por fungos endofíticos é maior do que qualquer outra classe de microrganismos endofíticos, provavelmente pela alta frequência de isolamento desses organismos (ZHANG et al., 2006). Na literatura, têm sido relatadas diversas biotividades de metabólitos produzidos por esses organismos (ZHANG et al., 2006; BLACKWELL, 2011; HARDOIM et al., 2015), como a atividade antibacteriana dos extratos fúngicos obtidos de endófitos isolados de Ophiopogon japonicus, planta tradicionalmente usada na medicina chinesa, os valores da taxa de inibição de um dos extratos foi $>90 \%$, considerada uma inibição alta, frente as bactérias Staphylococcus aureus e Cryptococcus neoformans, a concentração inibitória mínima do extrato foi de $20 \mu \mathrm{g} / \mathrm{ml} \mathrm{e} 80 \mu \mathrm{g} / \mathrm{ml}$, respectivamente e para controle positivo foi usada a gentamicina (LIANG et al., 2012). Essa mesma atividade foi encontrada nos extratos dos fungos endofíticos dos gêneros Phomopsis sp. e Botryosphaeria sp., isolados de espécies de Garcinia sp., quando testados contra duas cepas de Staphylococcus aureus, uma delas resistente à meticilina, a concentração inibitória mínima de ambos os extratos foi de $32 \mu \mathrm{g} / \mathrm{mL}$ para a cepa de $S$. aureus sem resistência e de $64 \mu \mathrm{g} / \mathrm{mL}$ para a cepa resistente à meticilina, o antibiótico vancomicina foi usado para o controle positivo e sua concentração inibitória mínima para as duas cepas foi de $1 \mu \mathrm{g} / \mathrm{mL}$ (PHONGPAICHIT et al., 2006). Para o endofítico Nigrospora sphaerica, isolado de Indigofera suffruticosa, também há relato de atividade antibacteriana contra $S$. aureus, quando cultivado em meio BDA e arroz, a concentração inibitória mínima de 1,56 mg/mL para BDA e de 0,39 mg/mL para o arroz (SANTOS et al., 2015).

Paralelamente, há relatos de atividade antifúngica, como a encontrada nos extratos de fungos endofíticos isolados de Artemisia annua, testados contra os fungos patógenos de plantas Gaeumannomyces graminis var. tritici, Rhizoctonia cerealis, Helminthosporium sativum, Fusarium graminearum, Gerlachia nivalis e Phytophthora capsici, o extrato de uma das cepas testadas, inibiu em $100 \%$ os três fungos patógenos e apresentou valores de concentração inibitória mínima de $1,5 \mathrm{mg} / \mathrm{mL}$ contra o patógeno G. gramini; de 0,4 mg/mL para P. capsici e de $R$. cerealis $0.4 \mathrm{mg} / \mathrm{mL}$ (LIU et al., 2001). Resultados interessantes também foram encontrados com os extratos dos fungos endofíticos Aspergillus flavus, Alternaria alternata e Colletotrichum gloeosporioides, isolados da planta medicinal Lannea coromandelica, que mostraram resultados significantes frente a ensaios de atividade antifúngica contra os fungos patógenos Candida albicans e Malassezia pachydermis, o extrato do A. flavus foi o único que apresentou valores significativos em relação a inibição do crescimento dos dois 
patógenos, com valores de zona de inibição $26.22 \mathrm{~mm}$ para C. albicans e de $16.72 \mathrm{~mm}$ para $M$. pachydermis; o extrato de A. alternata obteve valores significativos apenas contra M. pachydermis, com um valor total de zona de inibição de $15.11 \mathrm{~mm}$, já o extrato de C. gloeosporioides foi ativo apenas contra C. albicans, com a zona de inibição de $21.13 \mathrm{~mm}$, os valores de zona de inibição do controle positivo, fluconazol, foram de 42.8 $\mathrm{mm}$ para C. albicans e de $38.56 \mathrm{~mm}$ para M. pachydermis (PREMJANU et al., 2014).

Além da atividade antimicrobiana são encontrados estudos que demonstram a atividade antirradicalar de extratos de endófitos. Por exemplo, a atividade dos extratos de alguns fungos endofíticos isolados de espécies de Rhodiola sp. nos testes de DPPH, em especial, um dos extratos teve valores de EC50 de $1.54 \mathrm{mg} / \mathrm{mL}$, enquanto os controles vitamina $C$ e hidroxitolueno butilado tiverem valores de 1.28 e $3.13 \mathrm{mg} / \mathrm{mL}$, respectivamente (CUl et al., 2015). Outro caso, são dos endófitos Chaetomium sp., Aspergillus sp., Aspergillus peyronelii e Aspergillus niger, isolados de Eugenia jambolana, planta medicinal utilizada na Índia, que tiveram valores de atividade antioxidante de $80 \%$ para os dois primeiros e de $71 \%$ e $72 \%$, respectivamente para os dois últimos, o ácido ascórbico foi usado de controle positivo e teve um total de $98 \%$ de atividade antioxidante, além disso, os extratos ativos tiveram correlação positiva com o total de componentes fenólicos (YADAV et al., 2014).

Além de produzirem um grande número de substâncias com ações bioativas, outra característica interessante nos fungos endofíticos é a possibilidade da produção de substâncias com ação medicinal já comprovada, isoladas primeiramente em plantas (STROBEL et al., 2005; KHARWAR et al., 2011; MUSSI-DIAS et al., 2012). Um caso a ser citado é o do Taxol (Figura 13), que é um complexo diterpenoide utilizado no combate a diversos tipos de câncer, entre eles o de mama e ovário (STIERLE et al., 1993; MUSSI-DIAS et al., 2012). Esse composto foi primeiramente encontrado nas cascas da planta Taxus brevifolia, presente na costa oeste dos Estados Unidos e Canadá. Entretanto, por se tratar de uma planta de crescimento lento, cujo processo de obtenção do composto resultava na mortalidade da árvore, novas formas para se adquirir o Taxol foram buscadas (STIERLE et al., 1993; KUMARAN et al., 2010). Uma das formas utilizadas, foi o estudo dos fungos endofíticos presentes nessa planta. Por meio dele foi possível isolar o fungo endofítico Taxomyces andreanae, e com a análise do extrato fúngico, conseguiu-se identificar e isolar o Taxol, porém com um rendimento muito baixo (STIERLE et al., 1993; KUMARAN et al., 2010; MUSSI-DIAS et al., 2012). Outras espécies de Taxus foram investigadas com esse objetivo e, posteriormente, o taxol foi encontrado no extrato do fungo endofítico Pestalotiopsis versicolor, isolado de 
Taxus cuspidata, com um rendimento maior ao obtido empregando Taxomyces andreanae (KUMARAN et al., 2010).

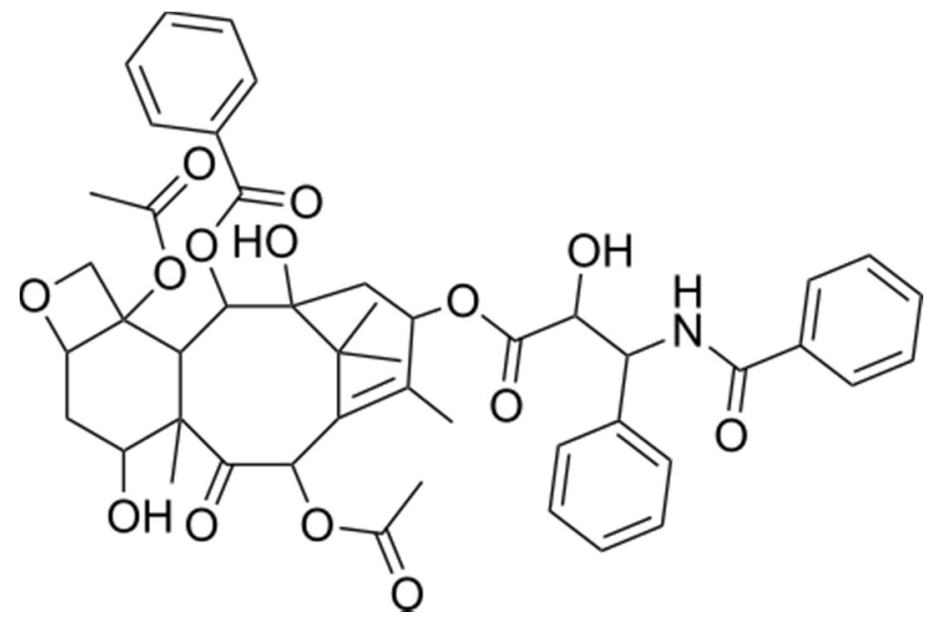

Figura 13. Estrutura do Taxol.

Outros casos de metabólitos de plantas encontrados em fungos endofíticos são os alcaloides Vimblastina e Vincristina (Figura 14), utilizados como medicamentos no combate ao câncer. Essas substâncias foram primeiramente isoladas da planta Catharanthus roseus. Através da pesquisa dos fungos endofíticos presentes nesse vegetal, foi isolado o fungo Fusarium oxysporum, e de seu extrato fúngico, encontrouse ambos os alcaloides (KUMAR et al., 2013). Um outro exemplo é a produção das flavolignanas silibina A e B (Figura 14), isoladas de Silybum marianum (Asteraceae), planta popularmente conhecida como cardomariano, e utilizada como fitoterápico no tratamento de desordens do fígado. Essas substâncias também foram produzidas pelo fungo endofítico Aspergillus iizukae, isolado da espécie (EL-ELIMAT et al., 2014).
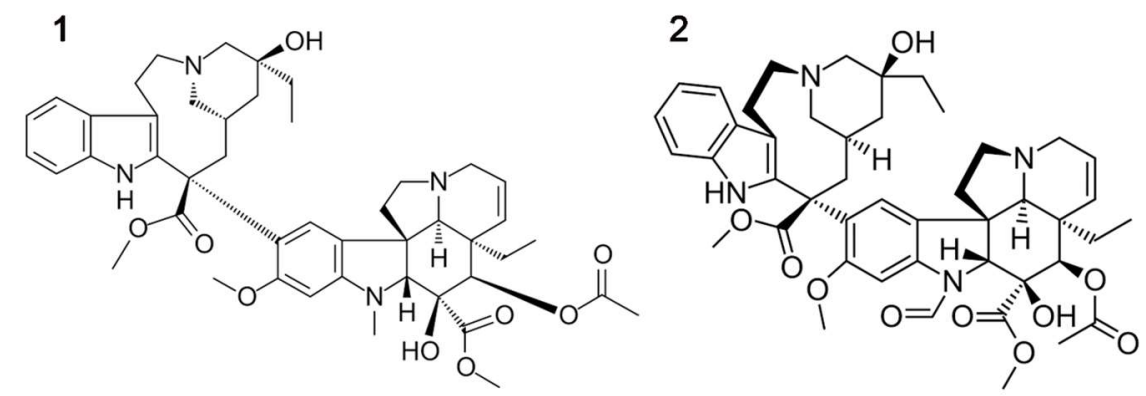<smiles>COc1cc(O)c2c(c1)O[C@H](c1ccc3c(c1)O[C@H](c1ccc(O)c(OC)c1)[C@H](O)C3O)[C@H](CO)O2</smiles><smiles>COc1cc(C2Oc3ccc([C@@H]4Oc5cc(O)cc(O)c5C(=O)[C@H]4O)cc3OC(CO)C2O)ccc1O</smiles>

Figura 14. Vimblastina (1), vincristina (2), flavolignanas silibina A (3) e B (4). 
Uma das hipóteses existentes para explicar a presença de metabólitos de plantas sendo produzidos por fungos endofíticos, seria a recombinação genética. Dados levados em consideração para essa hipótese são a relação extremamente próxima desses dois organismos, e a co-evolução dos fungos endofíticos e plantas existir desde os primórdios do período da conquista do ambiente terrestre pelos vegetais (SIMON et al., 1993; KRINGS et al., 2007). Durante esse tempo e devido à proximidade, podem ter ocorrido eventos de transferência horizontal de genes da planta para os fungos endofíticos. Assim, a recombinação genética pode ser o motivo de certos fungos possuírem a maquinaria necessária para a produção de metabólitos que são originários de plantas (ZHANG et al., 2006; QIU et al., 2010).

O estudo dos fungos endofíticos se mostra muito importante, devido ao fato desses indivíduos serem uma fonte prolífica de metabólitos secundários (ZHANG et al., 2006), e desses metabólitos terem demonstrado inúmeras bioatividades de interesse (STROBEL et al., 2005; ZHANG et al., 2006). Também é grande a diversidade de fungos encontrados em plantas, levando em consideração o fato de conhecermos uma pequena porcentagem da diversidade desses organismos (HAWKSWORTH, 2001; STROBEL \& DAYSE, 2003; BLACKWELL, 2011). Além disso, 51\% dos compostos isolados de fungos endofíticos até 2002 eram inéditos (STROBEL, 2002; SCHULZ \& BOYLE, 2005), mostrando que esses organismos são uma fonte de metabólitos bioativos e inéditos.

Em vista desses dados, o Brasil pode ser considerado um país com grande potencial de descoberta de novas espécies de fungos endofíticos, bem como de novos metabólitos, por causa de sua grande diversidade de espécies de plantas terrestres, cerca de 55.000 (BFG, 2015). Um trabalho de revisão de 2019 (SAVI et al., 2019), verificou que durante os anos de 2012 e 2017 foram publicados artigos sobre endofíticos, tanto fungos, quanto bactérias, de 54 espécies de plantas encontradas nos diferentes biomas do Brasil. Considerando apenas os trabalhos de fungos endofíticos em que há a identificação da planta e dos fungos, nesse período houve o estudo de 36 espécies de plantas, de 22 famílias diferentes. Em sua maioria, são espécies de Fabaceae, seguido por Asteraceae, Anacardiaceae e Rubiaceae (Figura 15). Pelos dados foi possível notar que as famílias mais estudadas são aquelas com importância para a agricultura, Fabaceae, que por exemplo, possui espécies de grande relevância para a agricultura, como a soja, já em comparação a estudos de endofíticos de plantas medicinais, os números foram menores 


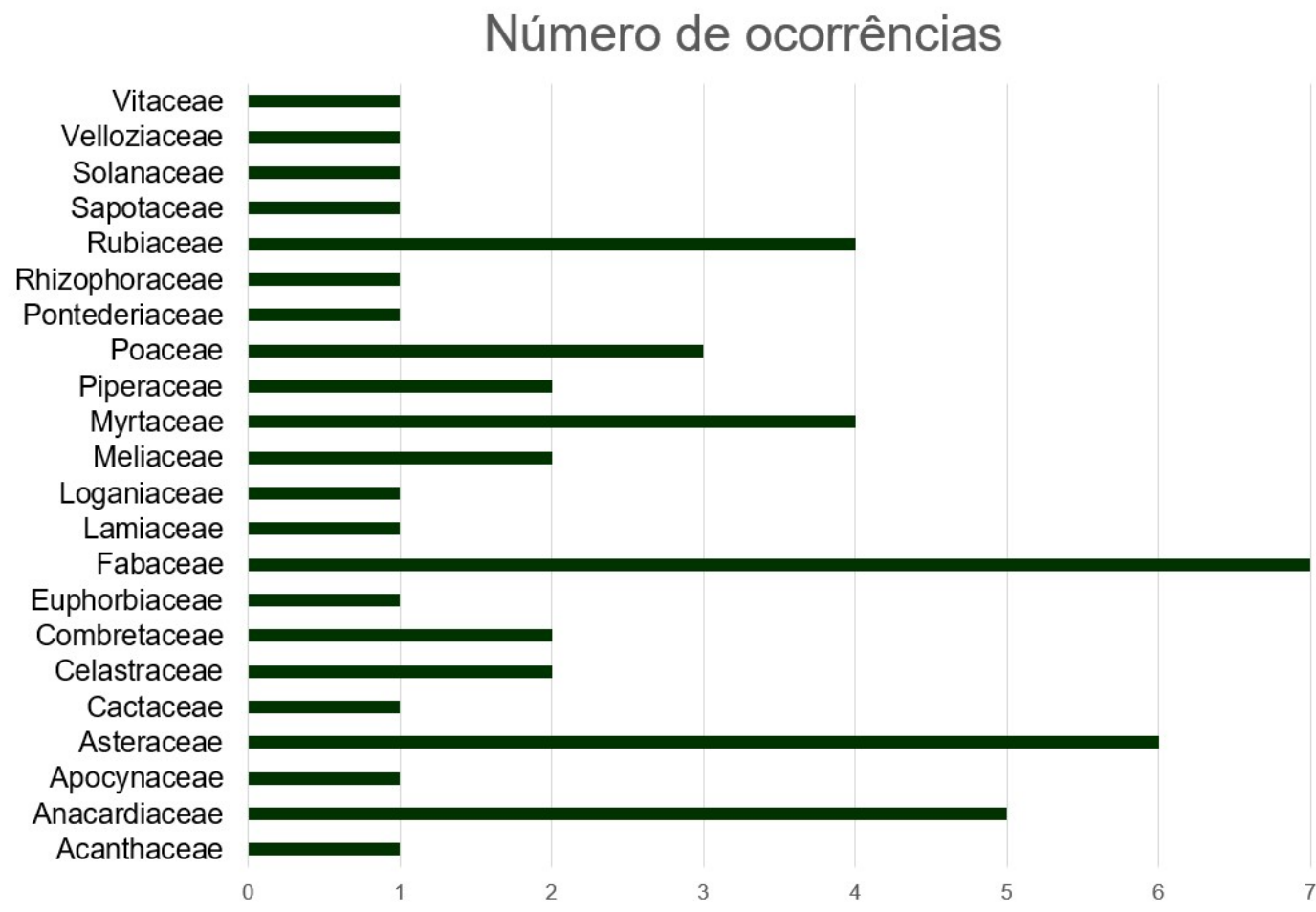

Figura 15. Número de ocorrências de estudos com fungos endofíticos oriundos de famílias de Angiospermas no período de 2012 - 2017 no Brasil (SAVI et al., 2019).

Em relação à diversidade de fungos, mais de 400 cepas foram identificadas, divididas nos filos Ascomycota, Basidiomycota e Mucoromycota (Figura 16). Foram identificados 83 gêneros, sendo Diaporthe o mais frequente, com um total de 22 ocorrências. Para efeitos de comparação, nos 42 trabalhos analisados, gêneros frequentes como Alternaria, Aspergillus e Penicillium tiveram um total de 9,7 e 8 ocorrências, respectivamente (SAVI et al., 2019).

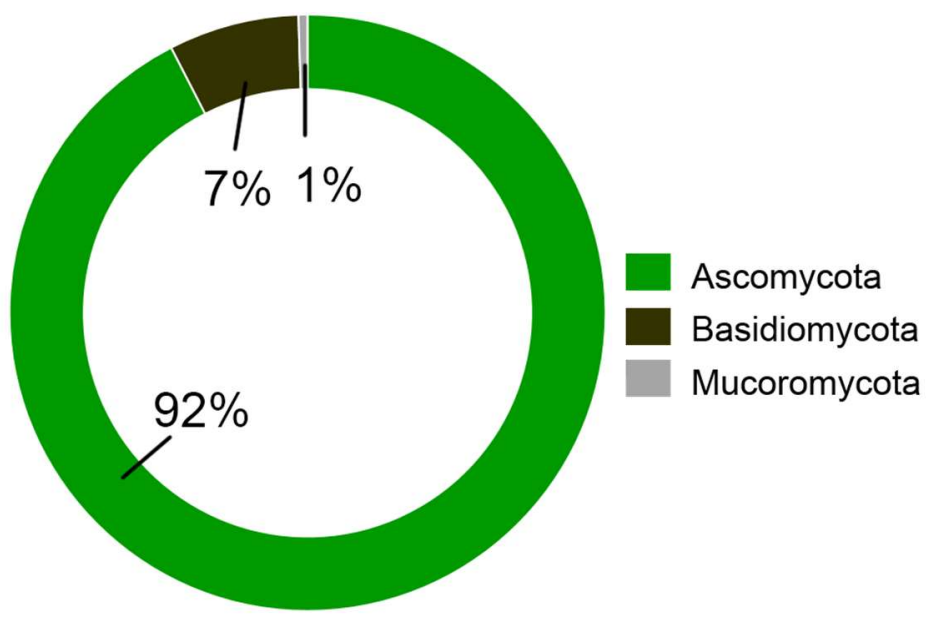

Figura 16. Porcentagem de ocorrência de filos de fungos descritos em trabalhos sobre fungos endofíticos durante os anos de 2012 - 2017 (SAVI et al., 2019). 
Em vista do grande potencial que os fungos endofíticos têm na caracterização de compostos que possuem diversas bioatividades de interesse, entre elas, a citotóxica, o objetivo geral deste trabalho foi contribuir com o conhecimento a respeito da diversidade química e biológica de fungos endofíticos associados a Baccharis oxyodonta. Desta forma, os objetivos específicos foram:

1. Isolar e identificar as cepas de Baccharias oxyodonta

2. Verificar o potencial da produção metabólica dessas cepas por meio da utilização de diferentes estratégias de cultivo

3. Avaliar a atividade citotóxica dos extratos

4. Utilizar a rede molecular obtida a partir dados de espectrometria de massas para identificar compostos e visualizar o impacto das diferentes condições de cultivo no perfil metabólico das cepas, bem como, usar como ferramenta na busca de extratos com potencial citotóxico

5. Com base nos resultados da atividade citotóxica obtidos anteriormente, selecionar os fungos de interesse para o crescimento em larga escala

6. Obter os extratos fúngicos de interesse e separar os seus constituintes químicos presentes no extrato

7. Identificar os constituintes químicos presentes nos extratos dos fungos selecionados

8. Realizar ensaios de atividade citotóxica com os constituintes químicos separados 


\section{Conclusões}

Os fungos endofíticos estão entre os microrganismos que apresentam grande potencial na obtenção de compostos que exibem atividades biológicas de interesse. Esse grupo apresenta uma grande diversidade, possuindo representantes de diferentes filos dentro do grande Reino Fungi. Sua importância compreende desde a relação fungo endofítico/planta hospedeira, a qual, muitas vezes, se mostra imprescindível para a planta, até a busca por novos medicamentos, que tenham atuação, por exemplo, no tratamento contra o câncer.

A planta escolhida para este trabalho foi Baccharis oxyodonta, os indivíduos deste gênero são bastante utilizados na medicina popular e os estudos em relação aos microrganismos relacionados são bem escassos. Este é o primeiro trabalho a estudar os fungos endofíticos de $B$. oxyodonta, realizando a identificação dos fungos associados aos indivíduos feminino e masculino da planta, além de avaliar o potencial citotóxico dos extratos dos fungos obtidos e realizar o isolamento e avalição da citotoxicidade das substâncias isoladas.

A quantidade de fungos encontrada no indivíduo feminino foi maior do que a do masculino (28 e 20, respectivamente). Em relação a diversidade de gêneros e famílias identificados em cada um dos indivíduos, os dados mostraram que ambos estão bem próximos. Nesse processo foram identificados os gêneros Alternaria, Aspergillus, Cladosporium, Colletotrichum, Penicillium, Periconia e Phomopsis; no indivíduo masculino e os gêneros/famílias Alternaria, Annulohypoxylon, Cercospora, Colletotrichum, Phomopsis e Preusia, Dydimellaceae e Strophariaceae no feminino.

O cultivo de todas as cepas foi realizado em três meios de cultivo distintos entre si (arroz, BDA e Czapek), a fim de se avaliar o perfil metabólico e obter uma produção modificada de compostos nos diferentes meios utilizados. Todos foram avaliados em relação a citotoxicidade e onze extratos foram considerados ativos, em sua maioria provenientes no meio Czapek e de cepas identificadas como Phomopsis. A forma que foi utilizada para analisar o impacto causado dos diferentes cultivos no metabolismo das cepas foi a construção de uma rede molecular através de uma análise metabolômica obtida a partir dos dados de espectrometria de massas dos 136 extratos obtidos, mais os 3 provenientes dos controles. Os resultados demostraram que os três meios causaram modificações no perfil metabólico das cepas e que, entre os três, o BDA foi o que gerou maior diversidade na produção de compostos. Além disso, foram identificados clusters de íons contendo diferentes substâncias das classes das xantonas, 
antraquinonas, amidas, lactonas sesquiterpenicas, ácidos graxos, isocumarinas, dicetopiperazinas e policetídeos.

Além disso, foram selecionadas duas cepas para serem cultivadas em larga escala, com base na atividade citotóxica e análise por CLAE-analítico. De Alternaria sp. 1 foram identificadas os policetídeos alternariol, alternariol-metiléter, altenusina e 5'metoxi-6-metil-bifenil-3,4,3'-triol. O alternariol ainda apresentou atividade de inibição moderada frente a linhagem tumoral HCT-116 (carcinoma de cólon), com $\mathrm{Cl}_{50}$ de 31,22 $\mu \mathrm{M}$. Já da outra cepa selecionada, Phompsis sp. 4, foram isolados cinco susbtâncias, das quais de três xantonas foram identificadas como sidowinina $B$, ácido 8-hidroxi-6metil-xantona carboxílico e phomopsixantona, esse último sendo um componente inédito em literatura. A sidowinina $B$ também foi avaliada através do ensaio do MTT, entretanto não foi efetiva contra as células tumorais HCT-116. 


\section{Referências Bibliográficas}

ALY, A.H.; DEBBAB, A.; PROKSCH, P. (2013). Fungal endophytes - secret producers of bioactive plant metabolites. Pharmazie 68: 499-505.

AZEVEDO, J.L. (1998). Biodiversidade microbiana e potencial biotecnológico. In: MELO, I.S.; AZEVEDO, J.L. Ecologia microbiana. Jaguariúna: Embrapa. p. 116-137.

AZEVEDO, J. L. (2014). Endophytic fungi from Brazilian tropical hosts and their biotechnological applications. In: Kharwar, R.N.; Upadhyay, R.; Dubey, N.; Raghuwanshi, R. Microbial Diversity and Biotechnology in Food Security. Springer, New Delhi. p.17-22

BACON, C.W.; GLENN, A.E.; YATES, I.E. (2008). Fusarium verticillioides: managing the endophytic association with maize for reduced fumonisins accumulation. Toxin Rev 27: 411-446.

BALDAUF, S.L. (2008). An overview of the phylogeny and diversity of eukaryotes. Journal of Systematics and Evolution 46(3): 263-273

BERBARA, R.L.L.; SOUZA, F.A.; FONSECA, H.M.A.C. (2006). III - Fungos micorrízicos arbusculares: muito além da nutrição. In: FERNANDES, M.S. Nutrição Mineral de Plantas. Viçosa. p. 54-85

Brazil Flora Group (BFG). Growing knowledge: an overview of seed plant diversity in Brazil. Rodriguésia 2015; 66: 1085-1113

BLACKWELL, M. (2011). The Fungi: 1, 2, 3 ... 5.1 million species? Am. J. Bot. 98: 426438

CANNON, P. F.; AGUIRRE-HUDSON, B.; AIME, M.C.; AINSWORTH, A.M.; BIDARTONDO, M.I.; GAYA, E.; HAWKSWORTH, D.; KIRK, P.; LEITCH, I.J.; LÜCKING, R. (2018).1. Definition and diversity. In: K. J. Willis (ed.), State of the World's Fungi. Report. Royal Botanic Gardens, Kew. pp. 4-11.

CASTRO, A.A.; OLIVEIRA, C.R.C.; ANJOS, D.S.; DE ORNELAS, E.I.; BITTENCOURT, V.R.E.P.; ARAÚJO, J.V.; SAMPAIO, I.B.M.; RODRIGUES, M.L.A. (2003). Potencial dos fungos nematófagos Arthrobotrys sp. e Monacrosporium thaumasium para o controle de larvas de ciatostomíneos de eqüinos (nematoda: cyathostominae). Rev. Bras. Parasitol. Vet. 12(2): 53-57 
CHAPLA, V. M.; BIASETTO, C. R.; ARAUJO, A. R. (2012). Endophytic fungi: An unexplored and sustainable source of new and bioactive natural products. Rev. Virtual Quim. 5: 421-437.

CLAY, K. (1988). Fungal Endophytes of Grasses: A Defensive Mutualism between Plants and Fungi. Ecology 69(1): 10-16.

CUI, J.-L.; GUO, T.-T.; REN, Z.-X.; ZHANG, N.-S.; WANG, M.-L. (2015). Diversity and antioxidant activity of culturable endophytic fungi from alpine plants of Rhodiola crenulata, R. angusta, and R. sachalinensis. PLOS ONE, 10(3), p.e0118204.

EL-ELIMAT, T.; RAJA, H.A.; GRAF, T.N.; FAETH, S.H.; CECH, N.B.; OBERLIES, N.H. (2014). Flavonolignans from Aspergillus iizukae, a Fungal Endophyte of Milk Thistle (Silybum marianum). J. Nat. Prod. 77: 193-199

ESTRADA, A.E.R.; JONKERS, W.; KISTER, H.C.; MAY, G. (2012). Interactions between Fusarium verticillioides, Ustilago maydis, and Zea mays: an endophyte, a pathogen, and their shared plant host. Fungal Genet Biol. 49: 578-587.

Fungos in Flora do Brasil 2020 em construção. Jardim Botânico do Rio de Janeiro. Disponível em: <http://floradobrasil.jbrj.gov.br/reflora/floradobrasil/FB128479>. Acesso em: 01 Set. 2019

GANESAN, A. (2008). The impact of natural products upon modern drug discovery. Current Opinion in Chemical Biology. 12:306-317

GAO, X.-X.; ZHOU, H.; XU, D.-Y.; YU, C.-H.; CHEN, Y.-Q.; QU, L.-H. (2005). High diversity of endophytic fungi from the pharmaceutical plant, Heterosmilax japônica Kunth revealed by cultivation-independent approach. FEMS Microbiology Letters 249(2): 255266.

GAYA, E.; KOOJI, P.W.; DENTINGER, B.T.M.; GRIGORIEV, I.V.; NAGY, L.G.; STAJICH, J.; COKER, T.; LEITCH I.J. 2. (2018). 2. Fungal tree of life. In: K. J. Willis (ed.), State of the World's Fungi. Report. Royal Botanic Gardens, Kew p:17-12.

HARDOIM, P.R.; OVERBEEK, L.S.; BERG, G.; PIRTTILÄ, A.M.; COMPANT, S.; CAMPISANO, A.; DÖRING, M.; SESSITSCH, A. (2015). The hidden world within plants ecological and evolutionary. Microbiol Mol Biol Ver. 79: 293-320

HAWKSWORTH, D.L. (2001). The magnitude of fungal diversity: the $1 \pm 5$ million species estimate revisited*. Mycol. Res. 105(12): 1422-1432 
HAWKSWORTH, D.L. (2004). Fungal diversity and its implications for genetic resource collections. Studies in mycology 50: 9-18.

HOBBIE, E. A., \& BOYCE, C. K. (2010). Carbon sources for the palaeozoic giant fungus Prototaxites inferred from modern analogues. Proceedings of the Royal Society B: Biological Sciences, 277(1691), 2149-2156.

HODGSON, S.; CATES, C.; HODGSON, J.; MORLEY, N.J.; SUTTON, B.C.; GANGE, A.G. (2013). Vertical transmission of fungal endophytes is widespread in forbs. Ecology and Evolution 4(8): 1199-1208

HONDA, N.K. \& VILEGAS, W. (1998). The chemistry of lichens. Química Nova 21(6): $110-125$

JAMES, T.Y., et al. (2006) Reconstructing the early evolution of Fungi using a six-gene phylogeny. Nature 443(7113): 818-822.

JERÔNIMO, G.H.; JESUS, A.L.; MARANO, A.V.; JAMES, T.Y.; SOUZA, J.I.; ROCHA, S.C.O.; PIRES-ZOTTARELLI, C.L.A. (2014). Diversidade de Blastocladiomycota e Chytridiomycota do Parque Estadual da Ilha do Cardoso, Cananéia, SP, Brasil. Hoehnea 42(1): 135-163

KANAGAWA, A.L. \& NEVES, M.A. (2011). Biologia e Sistemática de Fungos, Algas e Briófitas. In: GUERRA, R. A. T. Ciências Biológicas - Caderno CB Virtual 2. João Pessoa: Universidade Federal da Paraíba. p.279-302.

KELLER, N.P. 2019. Fungal secondary metabolism: regulation, function and drug discovery. Nature Reviews Microbiology, 17: 167-180

KHARWAR, R.N.; MISHRA, A.; GOND, S.K.; STIERLE, A.; STIERLE, D. (2011). Anticancer compounds derived from fungal endophytes: their importance and future challenges. Nat. Prod. ReP. 28: 1208-1228

KRINGS, M.; TAYLOR, T.N.; HASS, H.; KERP, H.; DOTZLER, N.; HERMSEN, E.J. (2007). Fungal endophytes in a 400-million-yr-old land plant: infection pathways, spatial distribution, and host responses. New Phytologist 174(3): 648-657.

KUMAR, A.; PATIL, D.; RAJAMOHANAN, P.R.; AHMAD, A. (2013). Isolation, purification and characterization of vinblastine and vincristine from endophytic fungus Fusarium oxysporum isolated from Catharanthus roseus. Plos One 8: E71805 
KUMARAN, R.S.; KIM, H.J.; HUR, B.-H. (2010). Taxol promising fungal endophyte, Pestalotiopsis species isolated from Taxus cuspidata. Journal of Bioscience and Bioengineering 110(5): 541-546

LIANG, H.; XING, Y.; CHEN, J.; ZHANG, D.; GUO, S.; WANG, C. (2012). Antimicrobial activities of endophytic fungi isolated from Ophiopogon japonicus (Liliaceae). BMC Complementary and Alternative Medicine 2012, 12: 238-244

LIU, C.H.; ZOU, W.W.; LU, H.; TAN, R.X. (2001). Antifungal activity of Artemisia annua endophyte cultures against phytopathogenic fungi. Journal of Biotechnology. 88(3): 277282.

LORON, C.C.; FRANÇOIS, C.; RAINBIRD, R.H.; TURNER, E.C.; BORENSZTAJN, S.; JAVAUX, E.J. 2019. Early fungi from the Proterozoic era in Arctic Canada. Nature 570(7760):232-235

MARGULIS, L. \& SCHWARTZ, K.V. Cinco Reinos. (2001). Um Guia Ilustrado dos Filos da Vida na Terra, 3 ed. Rio de Janeiro: Guanabara-Koogan, pp.497.

MUSSI-DIAS, V.; ARAÚJO, A.C.O.; SILVEIRA, S.F.; ROCABADO, J.M.A.; ARAÚJO, K.L. (2012). Fungos endofíticos associados a plantas medicinais. Rev. Bras. PI. Med. 14: 261-266.

PEREIRA, A.L. \& PITA, J.R. (2005). ALEXANDER FLEMING (1881-1955) Da descoberta da penicilina (1928) ao Prémio Nobel (1945). Revista da Faculdade de Letras. 6: 129-151

PHILIPSON, M.N. \& CHRISTEY, M.C. (1986). The relationship of host and endophyte during flowering, seed formation, and germination of Lolium perene. New Zealand Journal of Botany. 24(1): 125-134

PHONGPAICHIT, S.; RUNGJINDAMAI, N.; RUKACHAISIRIKUL, V.; SAKAYAROJ, J. (2006). Antimicrobial activity in cultures of endophytic fungi isolated from Garcinia species. FEMS Immunology \& Medical Microbiology 48(3): 367-372.

PREMJANU, N.; JAYNTHY, C.; DIVIYA, S. (2014). Antifungal activity of endophytic fungi isolated from Lannea coromandelica. Int. J. Res. Pharm. Sci. 5(4): 304-308.

QIU, M.; XIE, R.; SHI, Y.; ZHANG, H.; CHEN, H. (2010). Isolation and identification of two flavonoid-producing endophytic fungi from Ginkgo biloba L. Ann Microbiol 60:143150 
RAVEN, P.H.; EVERT, R.F.; EICHHORN, S.E. (1996). Biologia Vegetal, 5a. ed. Rio de Janeiro: Guanabara Koogan, pp.192-224.

REDECKER, D.; KODNER, R.; GRAHAM, L.E. (2000). Glomalean Fungi from the Ordovician. Science 289(5486): 1920-1921

RODRIGUEZ, R. \& REDMAN, R. (2008). More than 400 million years of evolution and some plants still can't make it on their own: Plant stress tolerance via fungal symbiosis. J. Exp. Bot. 59: 1109-1114

SANTOS, I.P.; SILVA, L.C.N.; SILVA, M.V.; ARAÚJO, J.M.; CAVALCANTI, M.S.; LIMA, V.L.M. (2015). Antibacterial activity of endophytic fungi from leaves of Indigofera suffruticosa Miller (Fabaceae). Front. Microbiol. 6(350)

SAVI, D. C., ALUIZIO, R., \& GLIENKE, C.(2019). Brazilian Plants: An Unexplored Source of Endophytes as Producers of Active Metabolites. Planta Medica, 85(8), 619-636.

SCHARDL, C.L. \& PHILLIPS, T.D. (1997) Protective grass endophytes where are they from and where are they going? Plant Disease 81(5): 430-438

SCHULZ, B. \& BOYLE, C. (2005). The endophytic continuum. Mycol. Res. 109(6): 661686

SIMON, L.; BOUSQUET, J.; LÉVESQUE, R.C.; LALONDE, M. (1993). Origin and diversification of endomycorrhizal fungi and coincidence with vascular land plants. Nature 363(6424): 67-69.

SPATAFORA, J.W.; AIME, M.C.; GRIGORIEV, I.V.; MARTIN, F.; STAJICH, J.E.; BLACKWELL, M. (2017). The Fungal Tree of Life: from Molecular Systematics to Genome-Scale Phylogenies. Microbiol Spectrum 5(5):FUNK-0053-2016

SOUZA, R.D.; MENDONÇA, E.A.F.; SOARES, M.A. (2015). Atividade antagônica a microrganismos patogênicos por bactérias endofíticas isoladas de Echinodorus scaber Rataj. Summa Phytopathol. 41(3): 229-232

STIERLE, A.; STROBEL, G.; STIERLE, D. (1993). Taxol and taxane production by Taxomyces andreanae, an endophytic fungus of Pacific yew. Science 260: 214-216.

STROBEL, G. A. (2002) Rainforest Endophytes and Bioactive Products. Critical Reviews in Biotechnology 22(4):315-333

STROBEL, G. \& DAYSE, B. (2003). Bioprospecting for Microbial Endophytes and Their Natural Products. Microbiol. Mol. Biol. Rev. 67(4): 491-502 
STROBEL, G.; DAISY, B.; CASTILLO, U. (2005). The biological promise of microbial endophytes and their natural products. Plant Pathology Journal. 4(2): 161-176

TAKAHASHI, J.A.; LUCAS, E.M.F. (2008). Ocorrência e diversidade estrutural de metabólitos fúngicos com atividade antibiótica. Quim. Nova. 31(7): 1807-1813

THROCKMORTON, K.; WIEMANN, P.; KELLER, N.P. 2015. Evolution of Chemical Diversity in a Group of Non-Reduced Polyketide Gene Clusters: Using Phylogenetics to Inform the Search for Novel Fungal Natural Products. Toxins, 7:572-3607

WEBSTER, J. \& WEBER, R.W.S. (2007). Introduction to FUNGI - 3 ed. New York Cambridge University Press, pp. 1-32.

WHITTAKER, R. (1969). New Concepts of Kingdoms of Organisms. Science 163: 150160.

WOESE, C. \& FOX, G. (1977). Phylogenetic structure of the prokaryotic domain: The primary kingdoms. Proceedings of the National Academy of Sciences 74(11): 50885090.

YADAV, M.; YADAV, A.; YADAV, J.P. (2014). In vitro antioxidant activity and total phenolic content of endophytic fungi isolated from Eugenia jambolana Lam. Asian Pacific Journal of Tropical Medicine 7:S256-S261.

ZHANG, Y.; MU, J.; FENG, Y.; KANG, Y.; ZHANG. J.; GU, P.-J.; WANG, Y.; M., L.-F.; ZHU, Y.-H. (2009). Broad-spectrum antimicrobial epiphytic and endophytic fungi from marine organisms: isolation, bioassay and taxonomy. Mar. Drugs. 7: 97-112

ZHANG, H.-W.; SONG, Y.C.; TAN, R.X. (2006). Biology and chemistry of endophytes. Nat. Prod. Rep. 23: 753-771. 